\title{
Robotics and the Global Organisation of Production
}

\author{
Koen De Backer and Timothy DeStefano
}

\section{Contents}

Introduction

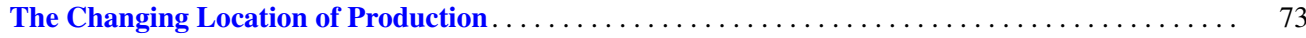

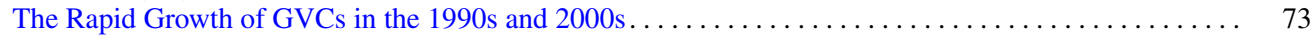

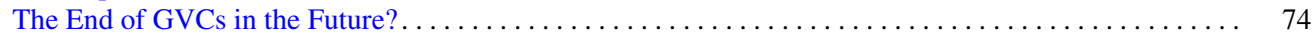

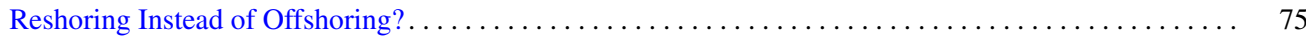

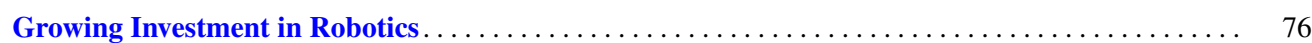

The Impact of Robotics on the Global Location of Production $\ldots \ldots \ldots \ldots \ldots \ldots \ldots \ldots \ldots \ldots \quad 78$

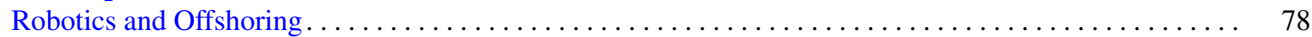

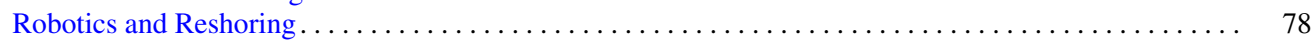

Robotics and the Reallocation of Resources within MNEs ......................... 79

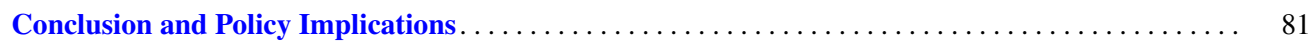

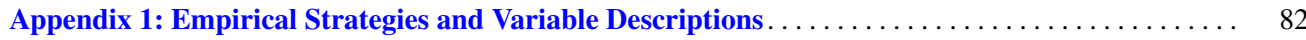

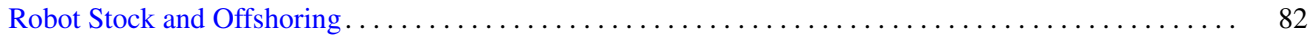

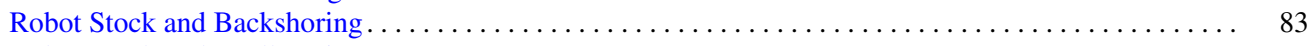

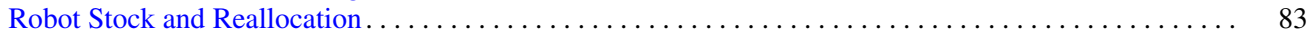

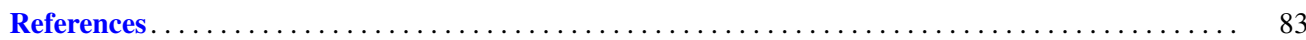

\section{Abstract}

The growing investment in robotics is an important aspect of the increasing digitalisation of economy. Economic

This contribution builds on the publication OECD (2018), "Industrial robotics and the global organisation of production", OECD Science, Technology and Industry Working Papers, No. 2018/03, OECD Publishing, Paris, https://doi.org/10.1787/dd98ff58-en. The opinions and arguments expressed herein do not necessarily reflect the official views of the OECD or its member countries. Koen De Backer is Head of Division and Tim DeStefano is Economist, both in the Structural and Industry Policy Division of the Directorate of Science, Technology and Innovation, OECD. The OECD, and not the Authors cited in the Contribution, retains all intellectual property in the Contribution.

K. De Backer $(\bowtie) \cdot$ T. DeStefano

Division of Structural and Industry Policy, Science, Technology and Innovation (STI), OECD, Paris, France

e-mail: Koen.DEBACKER@oecd.org research has begun to consider the role of robotics in modern economies, but the empirical analysis remains overall limited. The empirical evidence of effects of robotics on employment is mixed, as shown in the review in this chapter. The effects of robots on economies go further than employment effects, as there are impacts for the organisation of production in global value chains. These change the division of labour between richer and poorer economies. Robotics may reduce offshoring of activities from developed economies towards emerging economies. Global spreading of automation with robotics can lead to faster de-industrialisation in the development process. Low-cost jobs in manufacturing may increasingly be conducted by robots such that fewer jobs than expected may be on offer for humans even if industries were to grow in emerging economies. 


\section{Keywords}

Robotics · Economy · Manufacturing industry ·

Employment · Outsourcing · Global value chains

\section{Introduction}

Industrial robotics have become an integral component in the production processes of many firms around the world. The growing investment in robotics is one aspect of the increasing digitalisation of economy and society which is fundamentally changing the outlook of manufacturing industries across the globe. Governments in OECD and emerging economies are betting heavily on robotics to safeguard the competitiveness of their manufacturing industries, frequently supported by (direct) government support for research and adoption of robotics.

The rising prominence of robotics - and the digital (r)evolution more broadly-is increasingly attracting the attention of policy makers because of its possible effects on national economies. While high on the policy agenda in OECD economies, the impacts of new digital technologies are however uncertain and not well understood in general. The economic literature has recently begun to consider the role of robotics in modern economies but the (empirical) analysis remains overall limited. One exception is the rapidly growing number of studies discussing the employment impacts of robotics. Indeed, the discussion around robotics has centred especially on the implications of labour markets-especially in developed economies-as robots are expected to have a major impact on employment.

There is a widespread concern that new technologies might destroy a large number of jobs and cause "technological unemployment". Some economists believe that many of the jobs today will be undertaken by robots in the coming years (Brynjolfsson and McAfee 2014; Ford 2009). ${ }^{1}$ Robots are now capable of replacing a host of routine tasks performed within the firm and as their capabilities improve their ability to carry out non-routine tasks will increase. As for the types of jobs thought to be the most at risk to industrial robots and automation, these include blue collar jobs and routine occupations, while the groups of employees who are most at risk of wage decline or job lose are low-skilled males (Graetz and Michaels 2015; Acemoglu and Restrepo 2017; and Frey and Osborne 2017). But the empirical literature has produced mixed results until now. For example, while

\footnotetext{
${ }^{1}$ Widely cited work by Frey and Osborne (2017) suggests that potentially $47 \%$ of US employment may be threatened by computerisation and automation in the future. Comparable exercises have produced similar results for other countries, all pointing to a significant to large impact of robots and automation.
}

Acemoglu and Restrepo (2017) do find a negative impact of robots on employment and wages, Graetz and Michaels (2015) find only marginal effects on hours worked. Also OECD (2016) has concluded that the effects of robots on employment may be significantly smaller than what others have projected.

In addition to potential employment effects, some empirical work has analysed the effect of robotics on (labour) productivity. Graetz and Michaels (2015) report for a panel of 17 countries over the period 1993-2007 a positive impact of robots on labour productivity as well as total factor productivity - and thus economic growth. In discussing the future of robots, also BCG (Sirkin et al. 2015) expects a strong rise of productivity as a result of the wider adoption or robotics in manufacturing.

But the potential effects of robots on national economies go further than employment and productivity effects. Increased robot use, fuelled by the continuous decline in the price of robots and the increased dexterity of machines, can be expected to increasingly impact existing/future production technologies and the organisation of production within socalled Global Value Chains (GVCs). In economic terms, robots can be considered as a close substitute for lowerskilled labour and a complement to higher-skilled labour. ${ }^{2}$ Significant investments in robotics will alter relative factor endowments and thus factor costs in countries and this will/may change the location of production.

Robotics may limit the offshoring to emerging economies and promote the reshoring of activities back to OECD economies (De Backer et al. 2016; Dachs and Zanker 2015). ${ }^{3}$ Increased automation and robotics will overall decrease the importance of labour costs in total production costs, hence making the (re-) location of productive activities in OECD economies (again) more attractive. This is exacerbated by the fact that the gap in hourly wages between emerging and developed economies is decreasing and robots continue to become more economical. Differences in the cost of production between developed and emerging markets may thus narrow further, encouraging firms to restructure their global activities (Finley et al. 2017; De Backer and Flaig 2017).

\footnotetext{
${ }^{2}$ The current systems of robotics replace primarily the "routine" activities of lower-skilled labour while higher-skilled labour is (still) needed to handle, monitor and if necessary to intervene, the machines. Future robots will be more autonomous and self-learning, potentially diminishing the complementary character towards higher-skilled labour. ${ }^{3}$ De Backer et al. (2016) reported that the aggregate evidence on reshoring is until now rather limited which stands somewhat in contrast to the anecdotal and survey evidence on this new phenomenon. Also the Eurofound report "European Monitor of Reshoring Annual Report 2016" notes that reshoring is a relevant phenomenon in the EU, not decreasing in size but that further data and research are needed to confirm whether it is growing.
} 
This may be particularly pertinent for firms in developed countries who previously have offshored jobs to developing countries to benefit from lower labour costs (Lewis 2014; UNCTAD 2016). While mostly anecdotal, there are a host of examples of botsourcing (i.e. firms building new factories in the home country which are based on highly automated production plans) including Philips and Parkdale (Clifford 2013; Markoff 2012). Adidas recently opened a shoe factory in Germany called a Speedfactory with the objective of getting new shoe designs to consumers faster (Box 1).

This paper uses historic data on robots investments across industries and countries to deepen the analysis and to study the specific effects of robots on the location of production. In the following section, the paper provides a short overview of the changing location of production, which seems to pick up especially in recent years with GVCs drastically changing in nature. The following section provides empirical evidence on the growing importance of industrial robotics in today's manufacturing. The Impact of Robotics on the Global Location of Production section then analyses the links between these growing investments in robotics and the changes in production location across countries and industries; specific attention is paid to recent trends in offshoring and reshoring as well as the reallocation of resources within Multinational Enterprises (MNEs). One important aspect that has to be kept in mind is that the robotics revolution is (only) in its beginning stages, meaning that the potential impacts are just starting to emerge. The findings in this paper have to be interpreted in the light of this and most likely only signal more important effects to emerge once the robotics revolution is taking place.

\section{Box 1 Speedfactory Adidas}

Following the decision of one of the company's major competitors, Nike, to produce shoes through a robotised system in the United States, the world-known sport footwear German company Adidas decided to adopt a similar strategy by bringing production back from Asia to Germany. The first robotised plant has been opened in Ansbach in Southern Germany while the company also plans to establish a Speedfactory in the United States in 2017. Together, both factories are expected to produce a minimum of 1 million pairs of shoes every year. About 160 new jobs are expected to be created at the German plant, mostly highly skilled labour to maintain the robots. Bringing production back from China and Vietnam will help the company to offset long shipping times but also the rising cost of labour in some Asian countries. More importantly, it will also help Adidas to meet the demand for rapid innovation in designs and styles. Based on the current supply chain model, the average industry time for shoes to reach consumers (from design to delivery) takes 18 months (unless transported by plane). Within a Speedfactory, however, the use of robots and 3D printers enables shoe components to be produced and assembled in-house, reducing the expected delivery time (from virtual design to a store shelf) to less than a week (The Economist 2017).

\section{The Changing Location of Production}

\section{The Rapid Growth of GVCs in the 1990s and 2000s}

The rapid growth of GVCs has been an important driver of globalisation during the past decades. Because of successive rounds of trade (and investment) liberalisation and rapid progress in Information and Communication Technologies (ICTs), it became easier — and profitable—for companies to offshore activities over large distances. Production processes have become more geographically dispersed as companies increasingly locate different production stages across different countries through a network of independent suppliers and their own affiliates. Within these GVCs, intermediate inputs such as parts and components are produced in one country and then exported to other countries for further production and/or assembly in final products. As a result, production processes have become internationally fragmented and products increasingly "made in the world".

After their explosive growth during the early 2000s, GVCs have gradually become the backbone of the global economy and dramatically changed its functioning. The result is that global production nowadays spans a growing number of companies, industries and countries and a number of emerging economies have become economic powerhouses because of GVCs. The large flows of goods, services, capital, people and technology moving across borders within these international production networks have resulted in a growing interconnectedness between countries (OECD 2013).

GVCs have become longer and more complex since their emergence in the 1980s. Production stages of a growing number of goods-more traditional products like textiles as well as more technology-intensive products like, e.g. electronics-and increasingly also services are spread out across a multiple of locations. This in turn has resulted in growing trade and transport flows over time. The organisation of production in long and complex GVCs to take advantage of optimal location factors for specific stages of production across the globe has shown its advantages for companies in terms of productivity, efficiency, scale economies, etc. 


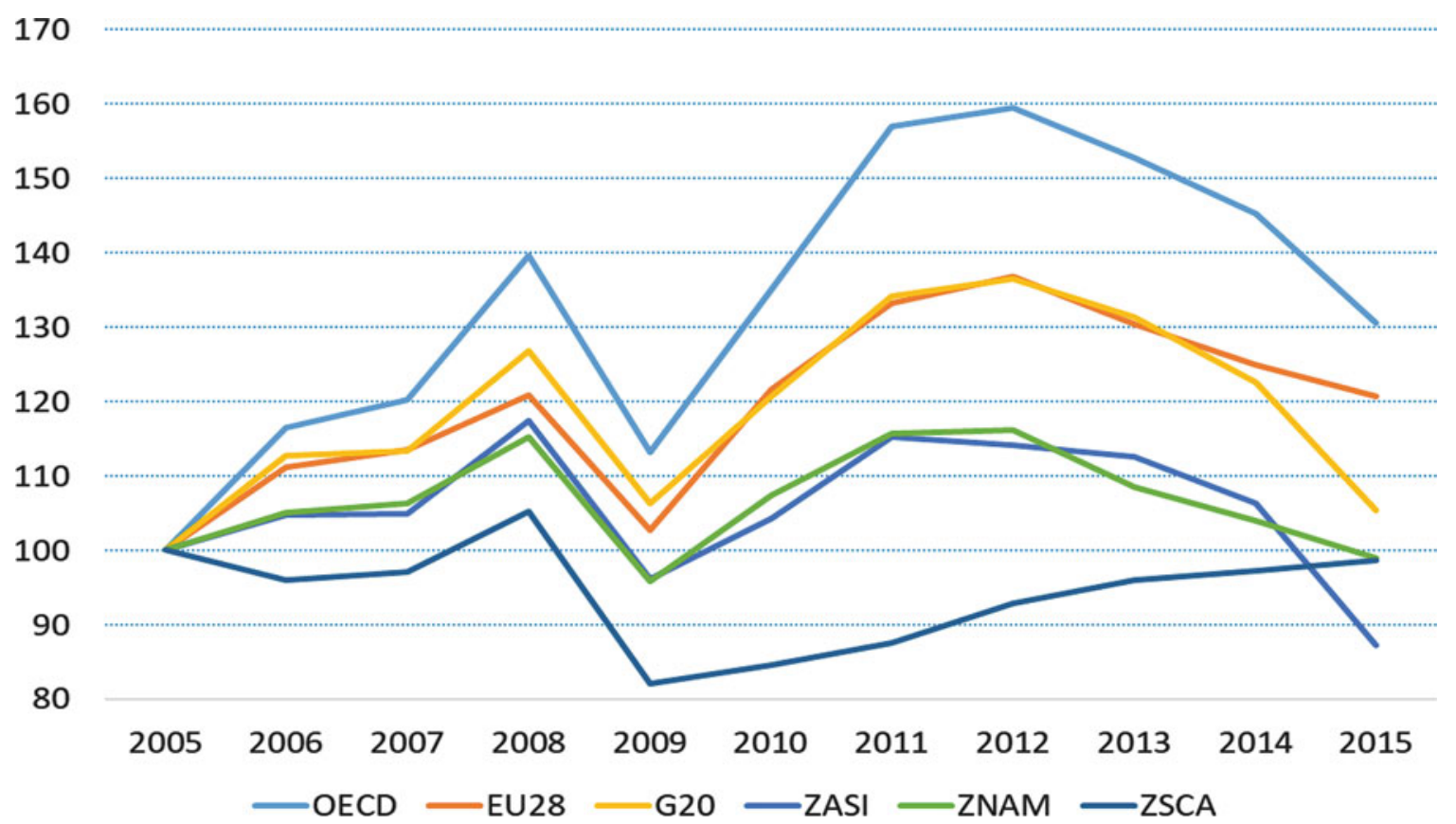

Fig. 1 Foreign value added of exports (index based on 2005). Source: De Backer et al. OECD—2018 TiVA database

The global dimension of economic integration has expanded rapidly as emerging countries such as the People's Republic of China, India and Brazil have become major players in the global economy, in part because of their increasing participation in GVCs. Numerous activities especially in manufacturing have been relocated to emerging economies as sourcing inputs from low-cost producers, either within or outside the boundaries of the firm, lowered production costs. The emergence of GVCs has allowed emerging economies to integrate in the global economy faster than in the past. Countries are able to specialise in a certain production activity according to their comparative advantage instead of developing the whole value chain itself (OECD 2013). Participation in GVCs is often viewed by governments as a fast track to industrialisation and strategies to increase the participation within GVCs are essentially part of economic development policies.

The emergence and growth of GVCs have been largely documented in recent years due to new evidence. Until recently, the empirical evidence on GVCs mainly consisted of case studies of specific products; early examples include the Barbie Doll (Tempest 1996; Feenstra 1998) and an average "American" car (WTO 1998). While these case studies offered interesting anecdotal evidence, more stylised analysis of the geographical distribution of costs, value added and profits has subsequently received a great deal of attention, in particular the well-known studies of Apple products (Linden et al. 2009; Dedrick et al. 2010). Afterwards, the OECD developed new aggregate - at the industry, national and global level-measures ${ }^{4}$ and has documented the rapid growth of

${ }^{4}$ See OECD's Trade in Value Added Database. A similar initiative is the World Input-Output Database. these global production networks. OECD (2013) discussed this new empirical evidence in detail and analysed the important implications of these GVCs of different policy domains (including trade, investment, competiveness, etc.).

\section{The End of GVCs in the Future?}

In contrast to the ever-growing length and complexity of GVCs in the past, the international fragmentation of production appears to have lost momentum in recent years. A (limited) consolidation of GVCs had already been observed during the economic crisis in 2008/2009, but trade as well as GVC growth picked up again thereafter. But new OECD results show that the foreign value added of exports-which is largely considered to be one important indicator of GVCs, see OECD (2013)—shows a downward trend (Fig. 1). The recent trade and GVC slowdown is increasingly argued to stem from more structural determinants-in addition to more conjunctural factors-suggesting that a new normal of GVCs may be at the horizon. Illustrating this is the growing popularity of the concept of "peak trade".

As the continuous expansion of GVCs may (have) come to an end, concerns about future production, trade and economic growth are rapidly rising in countries. Trade has traditionally been an important driver of productivity and economic growth of economies. One question that is increasingly raised in discussions on (the future of) globalisation is whether the relationship between trade and GDP growth has been undergoing a structural shift in recent years. It is clear that a slowdown of trade within GVCs will rapidly have consequences for the global economy. Likewise, a new era of GVC 
dynamics will most likely result in a re-configuration of the international production landscape with significant shifts in competitiveness between regions and countries.

Different factors will (simultaneously) determine the future of GVCs as discussed in detail in De Backer et al. (2018) simulating how production and trade within GVCs may look like in 2030. On the one side, there are factors that have promoted the growth of GVCs in the past and these are expected to facilitate the future expansion of GVCs; thus, business as usual. New communication technologies (i.e. the "C" in ICTs) which allow for the coordination of activities across large distances, the integration of emerging economies because of their low (labour costs) in manufacturing, the growing middle class in emerging economies which gradually changes (consumer) demand and results in fast growing end-markets in these countries, the efficient provision of "modern" services (telecommunications, logistics, business services, etc.) which are the glue that ties GVCs together and the rapid growth of MNEs are all major reasons why GVCs have expanded significantly since the 2000s.

On the other side, there are other factors that push for "a new normal" of GVCs; these include old and new factors, i.e. factors which are known to negatively impact GVCs but also emerging factors of which the possible effects on GVCs are less known. These factors are expected to increasingly challenge the organisation of production in longer and complex GVCs and may shape the future evolution of GVCs differently. Strongly rising wage costs in (some) emerging economies and the growing digitalisation of production because of new information technologies (i.e. the "I" in ICTs: robotics, automation, artificial intelligence, etc.) are expected to restore the competitiveness of developed economies and discourage further offshoring to emerging economies. In addition, rising transport costs, the hidden and extra-costs of offshoring including the problems in protecting proprietary knowledge abroad, the growing need to balance cost efficiency with risk diversification which comes at a cost, will make the international dispersion of production more expensive. Also future extra costs arising from policy efforts to internalise the environmental costs of (international) transport may make the international trade of goods and services more costly and thus affect the further offshoring of activities within GVCs.

Further on, the current organisation of production in long and complex GVCs has made companies less responsive to changes in customer demand while at the same time product customisation is becoming essential for firms to maintain a competitive edge. Some have argued that a shift from mass production to mass customisation is happening, hence the need for companies to be able to quickly respond to market signals.

Using different scenarios that mirror the most likely evolution of the different factors, the results in De Backer et al. (2018) indicate that the future of GVCs may indeed look quite different from the past. Dramatic decreases in international sourcing and intermediate trade are observed for the future up to 2030 with GVCs regressing back to their 2005 levels. The growing digitalisation of production will be most likely the biggest game-changer in this process, reversing the importance and length of GVCs and reorienting global production and trade back towards OECD economies.

\section{Reshoring Instead of Offshoring?}

Within this changing topography of GVCs and global production, reshoring of activities is expected to become increasingly attractive especially when these activities can be highly automated through the increased use of robots. A growing number of (media) reports seem to indicate that manufacturing companies in OECD economies are increasingly transferring activities back to their home country (backshoring) or to a neighbouring country (near-shoring). This stands in sharp contrast with the large offshoring of activities and jobs particularly in manufacturing away from developed economies over the past decades.

Policy makers in developed economies are banking on this and hope that reshoring will bring back jobs in OECD manufacturing. But within this ongoing debate on reshoring, considerable disagreement exists about how important this trend actually is and may become in the future. Some predict that reshoring will become a fundamental trend in the early twenty-first century, while more sceptical voices point to the overall small number of companies that have actually brought activities and jobs home. Indeed, while company surveys and anecdotal evidence suggest the growing importance of the reshoring trend, the more aggregate evidence indicates that the effects on national economies are (still) limited and only very recent (see for example De Backer et al. 2016). For example, claims that reshoring will result in a large number of extra jobs at home have not been received much empirical support. One reason is that reshored production is often highly automated through the use of robotics, meaning that only a limited number of additional jobs are created and that these jobs will increasingly be high-skilled.

The evidence also seems to indicate that the phenomenon of reshoring does not necessarily mean the end of offshoring nor that it will bring back all the activities that have been offshored during the past decades and restore manufacturing in OECD economies back to its level of the 1970s or 1980s. The evidence at the company and industry level demonstrates that offshoring is still taking place at the same time that reshoring is picking up. Further on, that same evidence tends to suggest that offshoring is still more important and larger today. Offshoring is still an attractive option since proximity to markets is a major reason for international investment: 
the large size and the strong growth of emerging markets is an important explanation for the attractiveness of emerging economies.

But after years of large-scale offshoring and outsourcing, it becomes clear that companies increasingly opt for more diversified sourcing strategies including reshoring and consider more options in structuring their production processes. In addition to global hubs in GVCs, production is expected to become increasingly concentrated in regional/local hubs closer to end markets both in developed and emerging economies. For some products low (labour) costs and long value chains will continue to form important competitive advantages for some time, but for other goods and services production will become increasingly organised at the more regional level.

\section{Growing Investment in Robotics}

During the last decades, robots have become increasingly prominent in manufacturing industries with parts of - and in some cases, complete-production processes automated. The robotisation of manufacturing first took off in OECD economies as it helped to compensate for high and rising labour costs and safeguard international competitiveness (Fig. $2^{5}$ ). But inmore recent years, strong robotics investment

\footnotetext{
${ }^{5}$ The data on robots in this paper are sourced from the International Federation of Robotics (IFR) and relate to the number of robots (no information is available on the size and the quality of robots). IFR defines an industrial robot as "an automatically controlled, reprogrammable, multipurpose manipulator programmable in three or more axes, which can be fixed in place or mobile for use in industrial automation applications" (IFR 2016b).
}

can also be observed in several emerging economies, often supported by their governments, as part of their industrialisation and development strategies. The growing robotisation is part of the broader trend of the digitalisation of manufacturing, with new digital technologies expected to radically change the outlook of industries. ${ }^{6}$ In combination with important advances in a number of complementary technologies, greater adoption of robotics is believed to be a key element in fostering "a next production revolution" (OECD 2017).

While costs of hardware and enabling software are expected to fall further, the performance of robotics systems will vastly improve. BCG (Sirkin et al. 2015) estimates that the cost of robots will decrease by $20 \%$ and their performance improve by around $5 \%$ annually over the next decade. Robots which are already widely used across manufacturing industries are rather suited for repetitive activities and very precisely defined environments. While some robots are equipped with on-board sensors, most of their movements are still preplanned and programmed. Machines are however expected to become more flexible due to the progress of artificial intelligence, self-learning and auto-correcting capabilities,

${ }^{6}$ OECD (2017) has distinguished three broad technologies underpinning the digitalisation of production; the Internet of Things (IoT), which enables the interconnection of machines, inventories and good; big data and embedded software which allow for the analysis of the huge volumes of digital data generated by these objects; and cloud computing which provides the ubiquitous availability of computing power. The uptake and growth of (industrial) robots or autonomous machines within sectors will result from the conjunction of these different technologies and applications.

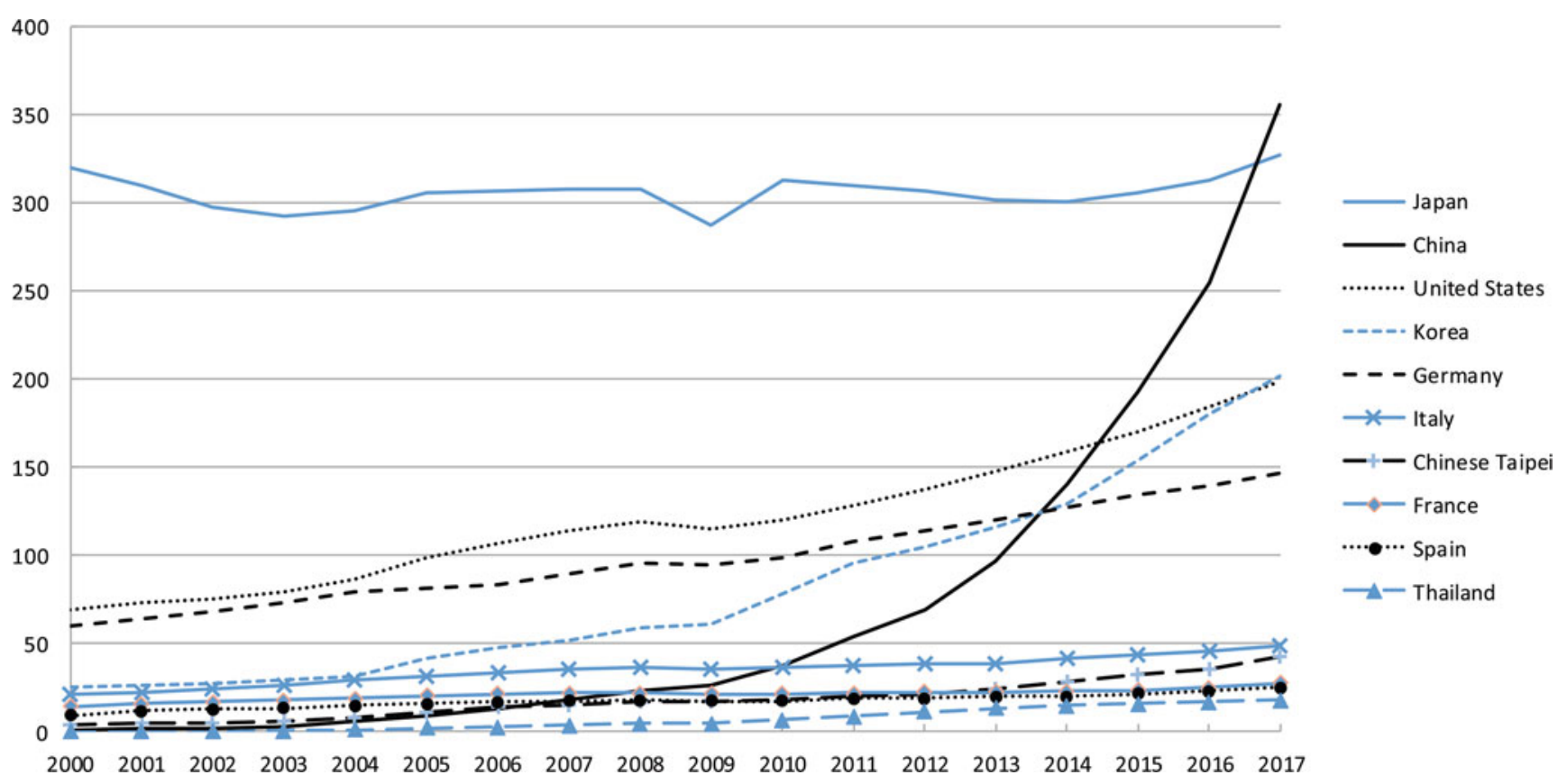

Fig. 2 Investments in industrial robots (units), by country, 2000-2017. Source: International Federation of Robotics (2016a) 


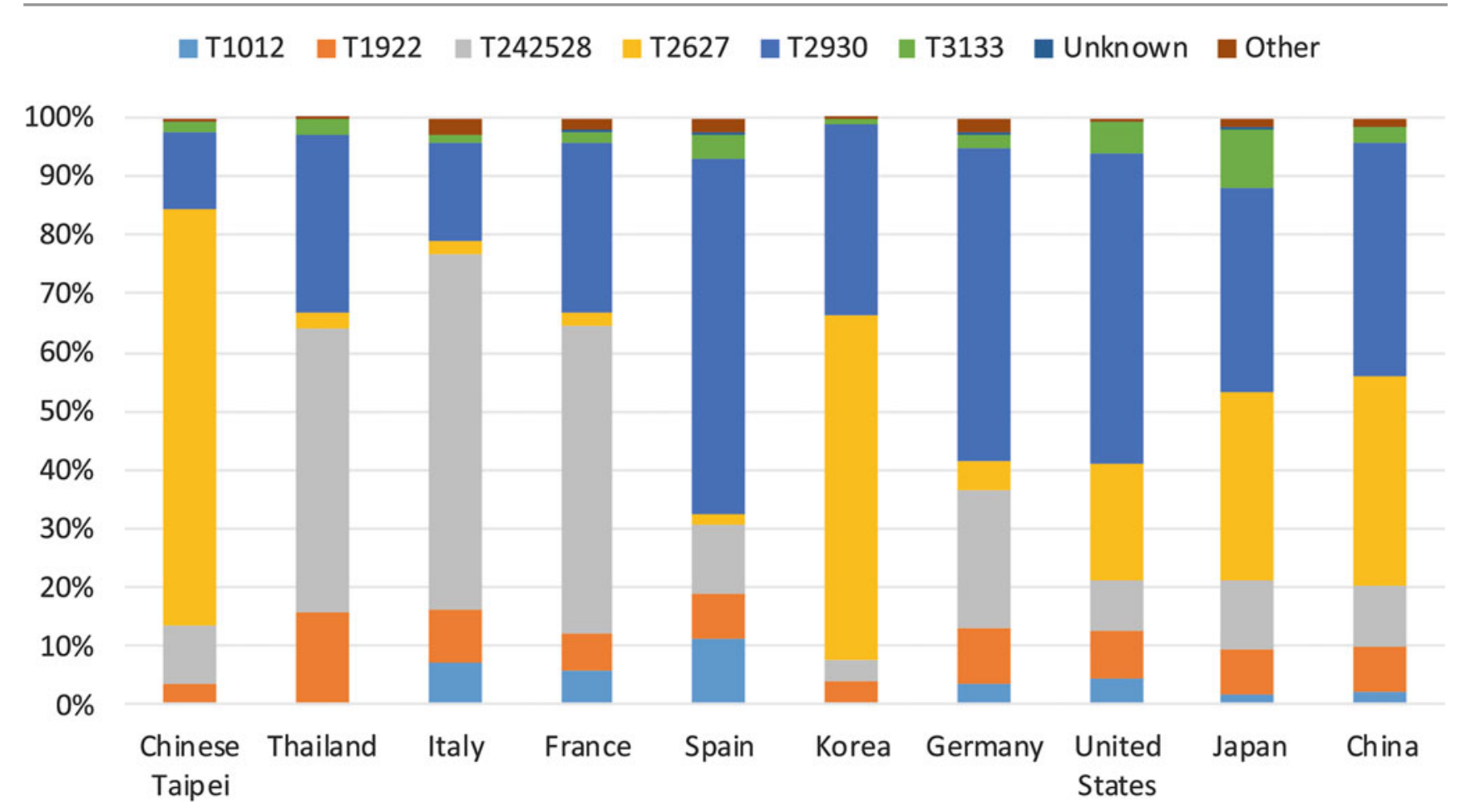

Fig. 3 Robot purchases by sector amongst highest users, 2017. Note: Sectors classified by ISIC version 4: T1012: food, beverage and Tabacco, T1922: petroleum products, chemicals, rubber and plastics, T242528: basic metals and machinery, T2627: computers and electrical machinery, T2930: motor vehicle and transport, T3133: other manufacturing and recycling, Other: to wood, paper and publishing non-metallic minerals and education and research. Source: Own calculations based on International Federation of Robotics (2016a) allowing them to perform a wider range of complex activities. As a result, machines will be increasingly able to do many tasks more precisely, cheaper and faster.

Robots are highly concentrated in a limited number of industrial sectors (Fig. 3): the majority of robot use (roughly $70 \%$ ) is concentrated within transport equipment, computers and electronics and chemical and mineral production and food and beverage production. For most economies, the transportation equipment sector is the largest user of industrial robots out of the economy. The deployment of robots in industries is generally dependent on a number of factors. First, technical requirements of the production process clearly determine the (further) usage of robots as some activities and jobs are easily automatable while others are not. Certain production tasks can only be replaced by very advanced robotics systems with a broad range of functions, which make them (too) expensive to implement. However, things are expected to change over time with higher performing robots - at a lower cost - being able to automate a growing number of activities and tasks.

Second, manufacturing industries in which labour costs account for a large(r) share in total production costs are more likely to invest in robotics because robots allow to save on labour and thus costs. But, third, location is another important determinant mediating this link between labour costs and wider robotics use. Industries located in emerging economies where labour costs are typically lower are less likely to adopt robots and automation compared to more developed (and thus higher labour cost) economies. The inflection point where robots become more cost efficient than human labour liescetris paribus-further in time for emerging economies. Interestingly however, some emerging economies are observed to heavily invest in robotics as a deliberate (government) strategy in order to compensate for their fast rising labour costs and/or to compete with the growing robotics manufacturing deployed in developed economies.

The high concentration of robots in sectors like transport equipment including automotive and electronics demonstrates the high stakes at play for emerging economies. The strong export position of these economies is largely based on their low labour costs in these industries. Strong investments in robots in developed economies may quickly result in the erosion of such a competitive advantage and make these activities exposed to reshoring of activities to developed economies. In other industries where emerging economies also benefit from their lower labour costs-e.g. garment and textiles-robots have not made a big inroad and are not expected to do so quickly. 


\section{The Impact of Robotics on the Global Location of Production}

In order to address new opportunities and challenges following digitalisation, companies are reorganising their domestic and global production processes and adopting new business models. In what follows, the impact of robotics on offshoring as well as reshoring is separately analysed, as well as the broader reallocation of resources within MNEs. ${ }^{7}$ Robots with a greater efficiency at lower costs may make it more costeffective for firms to keep production in the home country or to move production back or close there.

\section{Robotics and Offshoring}

The offshoring to emerging economies in the past has been motivated by the search for lower labour costs, in addition to the desire to be closer to large and growing consumer markets. Attracted by the large labour force in these countries, companies in developed economies-typically characterised by higher labour costs-relocated (labour-intensive) activities during the past decades. Since robotics allow for labour cost savings, it can be hypothesised that this cost motive of offshoring from developed economies will become less pressing. In combination with the rising wage costs in (some) emerging economies ${ }^{8}$ and persisting productivity differentials across countries, robotics are helping to lower the difference in the cost of production between developed and emerging economies. As robotic manufacturing becomes cheaper and offshoring more expensive, the cost/benefit analysis changes: instead of relocating activities away from home and sourcing inputs from abroad, production at home will increasingly become a viable/profitable alternative for companies.

Yet investments in robots are not only about saving on labour costs. Robotics are important tools to allow for more customised manufacturing, especially when artificially intelligent robots will increasingly become adaptable, programmable and autonomous. Industries in which market demand and consumer preferences change quickly have a lot to benefit from the usage of robots, compared to the alternative of offshoring-often far away-where suppliers do not al-

\footnotetext{
${ }^{7}$ The focus of the analyses is on the offshoring from and reshoring to developed economies. The group of developed economies consists of the "high-income economies" identified by the World Bank. A highincome economy is defined by the World Bank as a country with a gross national income per capita US\$12,236 or more in 2016.

${ }^{8}$ Nevertheless, rising wages have to be considered in combination with rising productivity. Further on, activities may be offshored from economies with rising wage costs to other emerging economies where wages are much lower and not rapidly increasing (for example from China to Cambodia).
}

ways produce according to the right specifications, resulting in quality issues and long delivery times. The deployment of robots can therefore help companies get new products to the market much quicker.

The hypothesis thus is that larger robot usage increases the attractiveness of (developed) economies for manufacturing activities and as a result may reverse the past/current offshoring trends. In order to analyse the potential effects of robotics on offshoring, the widely used Feenstra and Hanson (1996) measure of offshoring ${ }^{9,10}$ is related to investments in robotics across countries and industries over time. As such, the focus is on how robotics may change the extent of international sourcing of intermediates.

The results for the whole period 2005-2016 for developed economies do not directly seem to suggest a link between the growth in robots investments and offshoring (for a detailed discussion on the empirical model and variable construction, please see Appendix 1). But when focusing on the more recent years 2010-2016-i.e. a period characterised by rapidly rising investments in robotics - the results demonstrate a negative association of robotics investments (net of depreciation) with the growth of offshoring (Table 1). Industries in developed economies that increasingly invest in robotics witness a lower growth in offshoring, i.e. a decrease in the international sourcing of intermediates. In previous work, this negative association became larger as the labour intensity of industries increases, suggesting that robotics (help) hinder/stop the relocation of especially labour-intensive activities, as they help compensate for higher labour costs in developed economies. In this new analysis based on more recent data, this interaction effect disappears which may suggest that robotics are becoming more widespread across all manufacturing industries.

\section{Robotics and Reshoring}

The previous analysis suggests that robotics slow downand in some cases, stop-offshoring and thus help to keep manufacturing activities in developed economies. A slightly different question is if investments in robots will lead to the actual reshoring of activities to developed economies, i.e.

\footnotetext{
${ }^{9}$ Feenstra and Hanson called this measure an indicator of "outsourcing" although the indicator actually measures offshoring since it is defined as companies' purchases of intermediate goods and services-excluding energy intermediate inputs - from foreign providers (at arms-length and from foreign affiliates).

${ }^{10}$ The indicator has been calculated on the basis of OECD TiVA data which are up-to-date until 2016. In addition, a number of control variables such as labour intensity, demand and absorptive capacity (measured by patent stock) are included. These data are sourced from UNIDO, TiVA and PATSTAT databases, respectively. After merging these datasets with the statistics on robotics, the sample includes roughly 40 countries over the period 2000-2016.
} 
Table 1 Effects of growth in robotics on the growth of offshoring

\begin{tabular}{l|l|l}
\hline & HDC & \\
\hline Dependent var: Offshoring (annual growth) & $2005-2016$ & $2010-2016$ \\
\hline Robot stock (annual growth) & -0.001 & $-0.013^{* * *}$ \\
\hline & 0.00 & 0.00 \\
\hline Robot stock * Labour Intensity & -0.471 & -0.233 \\
\hline Labour Intensity & -0.35 & -0.25 \\
\hline & 0.236 & $0.292^{*}$ \\
\hline Patent Stock & -0.27 & -0.17 \\
\hline & -0.002 & -0.003 \\
\hline Demand & 0.00 & 0.00 \\
\hline & -0.007 & -0.014 \\
\hline Control Variables & -0.03 & -0.02 \\
\hline Year & & \\
\hline Country ${ }^{*}$ Industry & $\checkmark$ & $\checkmark$ \\
\hline$R$-squared & $\checkmark$ & $\checkmark$ \\
\hline Observations & 0.245 & 0.214 \\
\hline$N$ ote: Robust standar & 4,635 & 2,897
\end{tabular}

Note: Robust standard errors in parenthesis. Level of significance ${ }^{* * *} p<0.01,{ }^{* *} p<0.05,{ }^{*} p<0.1$

Source: Own calculations

bringing activities that were once offshored back home. De Backer et al. (2016) analysed the (re-)allocation of resources abroad and at home within groups of MNEs based on firmlevel data and found some evidence of reshoring in terms of capital investments but not in terms of employment. One reason put forward for these trends was that robotics are very capital intensive investments, but at the same time laboursaving. This also explains why the employment impact of reshoring in developed economies is often rather limited, and does not lead to the manufacturing renaissance of (certain) OECD economies as some have advocated.

This paper extends the empirical firm-level analysis as in De Backer et al. (2016) and includes robotics investments at the country-industry level (please see Appendix 1 for a detailed discussion on the empirical model and variable construction). The idea is to check if within groups of MNEs a transfer of productive resources (i.e. fixed capital and employment) takes place from the affiliates abroad to the headquarters and affiliates at home ${ }^{11}$ because of robotics investments. Interestingly, the results-now thus including more recent years-for the group of developed economies do show indications of backshoring in terms of employment over the most recent period 2010-2016 (Table 2). A negative change in aggregate employment abroad is associated with a positive employment growth in the home country within

\footnotetext{
${ }^{11}$ In order to check for this, the evolution of productive resources in affiliates abroad is split out in a positive and negative component (i.e. a negative coefficient for the negative growth abroad lends support for reshoring); see for more details De Backer et al. (2016).
}

the same business group, which thus give some support to the claims about the growing importance of backshoring in recent years.

Augmenting the model with robots investments-by interacting the negative/positive growth abroad with robots investments in order to see if there is more reshoring to home countries where robots investments are relatively more important ${ }^{12}$ - does however not get support from the model. No extra effect is observed from robotics on the reshoring of productive resources to developed home countries, neither in terms of fixed capital or employment. Also the recent reshoring seems not be driven by investments in robotics, i.e. home countries investing strongly in robotics do not witness a stronger reshoring of jobs in 2010-2016. All in all, while robotics seems to have a negative effect on the pace of offshoring, the results suggest that robots do not (yet) trigger a reshoring of activities to developed economies.

\section{Robotics and the Reallocation of Resources within MNEs}

The reallocation of resources within networks of MNEs is not a two-way street between affiliates abroad and the headquarters at home but instead happens between all affiliates mutually. By broadening the analysis beyond the reshoring of activities of MNEs to home countries, the potential effect of robotics on the total reallocation of resources across affiliates within groups of MNEs can be analysed. Because of their international networks, MNEs have a large (strategic and operational) flexibility in moving resources from one place to the other. The labour savings and increased production flexibility from robot use enable MNEs to shift production to other countries, for example, by locating production closer to the end customer so they can tailor and design goods based on the changing interests of the local market. Firms with plant facilities in multiple countries can quickly transfer product designs through CAD/CAM files between teams of robots making it easier for firms to shift production needs throughout the world. Greater advances in cloud computing and machine to machine communication will also facilitate real-time learning between robots in different locations and increase the responsiveness and efficiency of production (PWC 2014).

The objective of the next empirical analysis thus is to analyse if the (re-)allocation of productive resources within

\footnotetext{
${ }^{12}$ The robotics variable is constructed as the growth in robots stock of the home country relative to the average of the growth in robots stock in the countries where the group has affiliates; this in order to take into account the different geographical spread of MNE groups. Of course, this is only an indirect and rough proxy of the potential effect of robotics since the robotics is constructed on the country-industry level while the allocation of resources is based on firm-level data.
} 


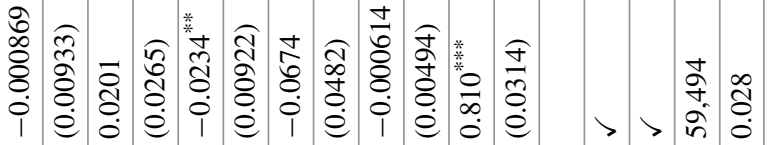

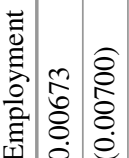

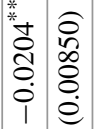

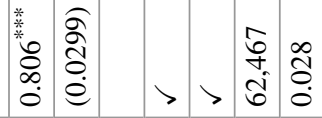

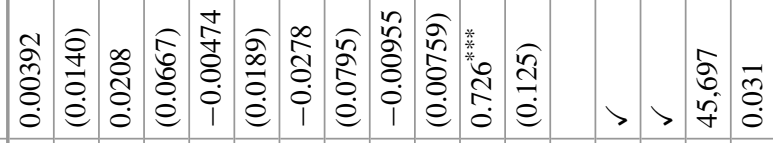

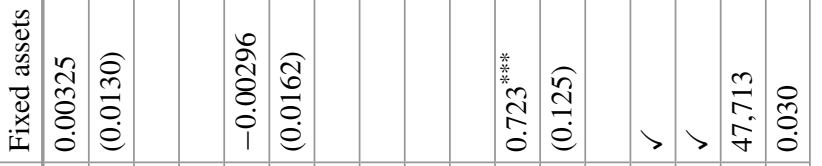

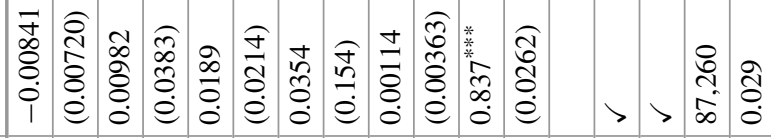

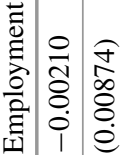

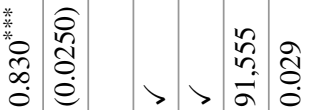

0
$\mathrm{o}$

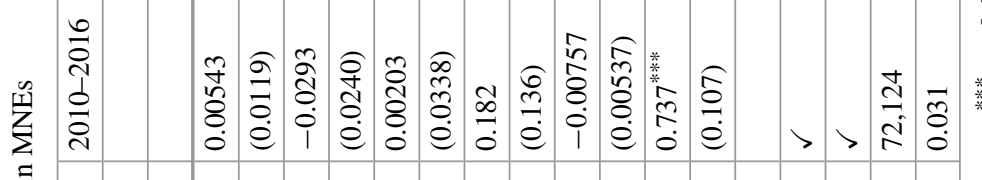

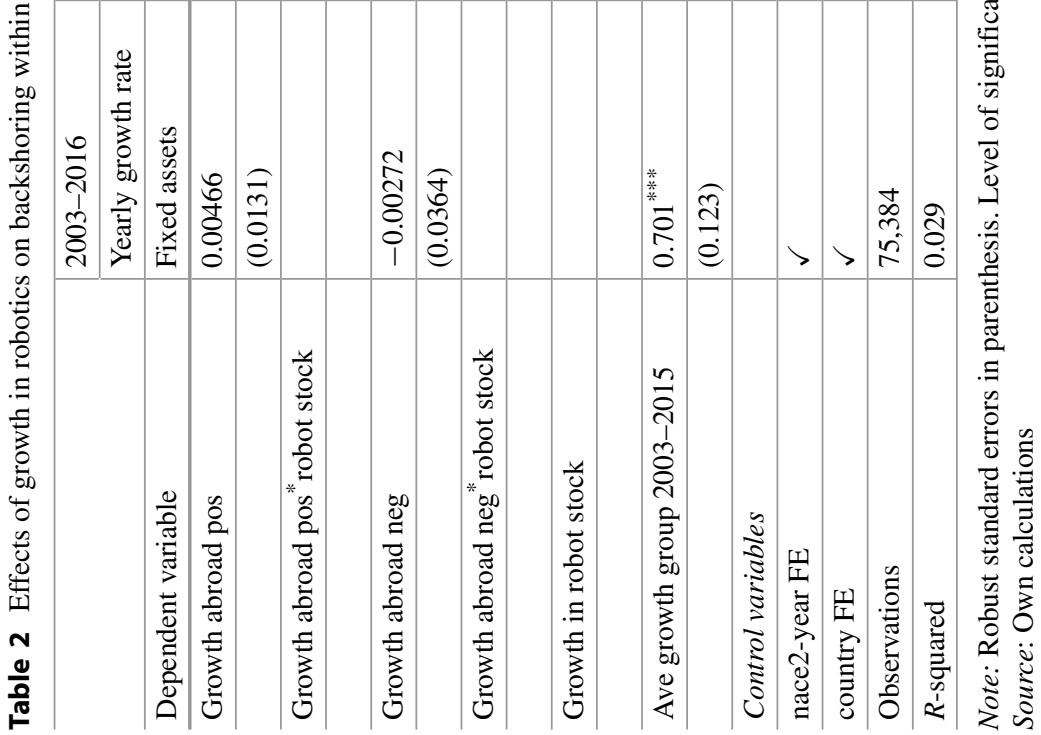


MNEs shifts relatively more towards countries that invest (more) heavily in robotics. Similar to the previous analyses on offshoring and reshoring, the discussion focuses on how robotics may increase the attractiveness of countries for manufacturing activities, but now in particular for investment by (foreign and domestic) MNEs. The same firm-level information on fixed capital and employment as in the previous analysis is used but now at the level of individual affiliates of MNEs, again linked to robotics stock in the country of the affiliate $^{13}$ (see Appendix 1 for details on the empirical model and data construction).

The results in Table 3 lend some support for the hypothesis that the reallocation of resources across affiliates of MNEs is driven in part by investment in robotics. A positive correlation of robot investment on employment growth is observed for MNEs with headquarters in developed economies. In particular, the results suggest that affiliates located in economies with strong growth in robotics investments, relative to the average group growth of the MNEs, seem to attract larger resources in terms of jobs. However, there is no effect on capital investment, and the employment effect disappears when focusing on only the more recent years 2010-2016.

\section{Conclusion and Policy Implications}

The analyses in this paper demonstrate that robotics may impact the location of production within GVCs. The most important finding is the negative effect that robotics may have on the offshoring of activities from developed economiesi.e. robotics seem to decrease the need for relocating activities away from developed economies. Yet, while robotics may thus keep production activities in developed economies, these same investments in robots do not seem strong or large enough to bring back activities that have been offshored in the past. In addition, there is mixed evidence about robotics being a major factor in attracting international investment, when analysing the effect of robotics on the international reallocation of resources within MNEs.

There are a number of reasons that may help explain the rather limited evidence found in this paper. First and foremost, it may be too premature to observe the potentially disruptive effects of robotics on the location of production. Investments in robots have grown significantly indeed but

\footnotetext{
${ }^{13}$ The robotics variable is now constructed as the growth in robots stock of the affiliate country relative to the average of the growth in robots stock in the countries where the group has affiliates; as in the previous analysis on backshoring, this is done in order to take into account the different geographical spread of groups of MNEs. Again, this is only an indirect and rough proxy of the potential effect of robotics (countryindustry level of robotics versus firm-level performance).
}

may have done so only recently and it can be expected that potential impacts will take some to materialise. If a robotics revolution is about to happen like some are arguing, one response this paper calls for is the need for further and followup research in the coming years.

Second, while information on robotics has become increasingly available across industries and countries including emerging economies, it should be taken into account that the available data only include information on the number (i.e. a count) of robots. Regretfully, no information is available on the size and especially the growing quality of robotsone can easily assume that new vintages of robot investments have a higher performance-but this is not reflected in the data.

Third, robots are only one part of the wider digital revolution that is currently taking place. Other developments including the Internet of Things, artificial intelligence, etc. will additionally contribute to the digital revolution and, consequently, it can be expected that companies will need to invest in complementary assets to fully benefit from their investment in robotics. The data in this paper do not include information on these other components of the digitalisation of manufacturing, which may mean that the effects of robots are somewhat underestimated.

The negative effect of robotics on offshoring that is found in this paper seems to be in line with the distinction made by Baldwin (2016) who argued about the differential effects of respectively communication and information technologies on the international fragmentation. The rapid progress in communication technologies has been one factor behind the rapid growth of GVCs in the past as these technologies allow for the monitoring and coordination of production activities across large distances. Information technologies, including robots investment, instead may curb the further international dispersion of activities and may make developed economies more attractive (again) for manufacturing activities. One reason is that information technologies reduce the share of labour costs in total production costs. A second reason is that information technologies allow companies to customise their products better and much faster, which is increasingly becoming important in a number of industries.

The effect of robotics on offshoring in developed economies, based on historical data, also supports the results of De Backer and Flaig (2017), who simulated the future of GVCs based on a number of scenarios for the future. They reported that one specific scenario, namely the rapid progress in information technologies including robotics, will increase the attractiveness of OECD economies for manufacturing activities. This would be reflected in a decreased sourcing of intermediates from abroad, lower levels of offshoring and a stronger export position of OECD manufacturing in global markets. 
Table 3 Effects of growth in robotics on the reallocation of resources within MNEs

\begin{tabular}{l|l|l|l|l}
\hline & $2003-2016$ & \multicolumn{2}{l}{$2010-2016$} \\
\cline { 2 - 5 } & Employment growth & Fixed asset growth & Employment growth & Fixed asset growth \\
\hline $\begin{array}{l}\text { Change in affliate stock/ave change } \\
\text { affiliates }\end{array}$ & $0.006^{* *}$ & -0.005 & 0.000 & -0.01 \\
\hline & & -00 & 0.00 & -0.01 \\
\hline Employment growth of group & $0.117^{* * *}$ & & $0.107^{* * *}$ & \\
\hline & -0.01 & & -0.01 & $0.134^{* * *}$ \\
\hline FA growth of group & & $0.134^{* * *}$ & -0.01 \\
\hline Control variables & & -0.01 & & \\
\hline Sector ${ }^{*}$ year & & & & \\
\hline Country ${ }^{*}$ year & & & & \\
\hline$R$-squared & & & & 0.029 \\
\hline Observations & 0.038 & 0.013 & 224,312 & 192,516 \\
\hline
\end{tabular}

Note: Robust standard errors in parenthesis. Level of significance ${ }^{* * *} p<0.01,{ }^{* *} p<0.05,{ }^{*} p<0.1$

Source: Own calculations

The evidence in this paper albeit preliminary-and the need for follow-up analysis using more recent data cannot be emphasised enough — seems to indicate that robotics may contribute to manufacturing competitiveness. Most OECD countries see digital production as a new source of competitiveness in restoring their position in manufacturing industries. This is reflected in the growing number of policy measures that several OECD countries have implemented or are in the process of implementing.

Faced with these economic challenges, also governments in emerging economies have identified robotics as a key determinant of their future economic success. The growth model of emerging economies which is largely based on low labour costs will come under increasing pressure if developed economies increasingly automate their manufacturing and are successful in keeping/attracting production activities at home. In a number of emerging economies, labour costs have been rising quickly which makes the option of automation and larger robot usage - at home or abroadincreasingly attractive, especially for companies who have offshored activities to these countries in search of low wages.

The likely outcome will be different across industries and countries. But, as robotics are getting cheaper and becoming more performant also in the number of activities they can be applied to, it can be expected that the so-called inflection point for investment in robots (BCG estimates this inflection point to be reached when using robots becomes $15 \%$ cheaper per hour than employing human staff) will come closer in a growing number of industries and countries. This process of growing automation, in developed as well as emerging economies, may further stimulate the process of premature de-industrialisation that has been observed recently in a num- ber of economies. While the traditional model of economic development involves a shift from agriculture over manufacturing to services, Rodrik (2015) reported that a number of emerging economies are de-industrialising quicker than expected. The fact that automation - in developed economies but increasingly also in emerging economies-may increasingly replace low-cost jobs risks that manufacturing will not be able to offer large numbers of jobs for the large labour supply in these countries.

\section{Appendix 1: Empirical Strategies and Variable Descriptions}

\section{Robot Stock and Offshoring}

The model used to estimate the effects of robot stock on offshoring is illustrated in Eq. (A.1):

$$
\begin{aligned}
& \text { off }_{\text {shore }} \text { ict }=\text { robot }_{i c t}+\text { robot }^{*} \text { labint }_{i c t}+\text { labint }_{i c t} \\
& + \text { Absorb }_{i c t}+\text { Demand }_{i c t}+\vartheta_{i}+\varepsilon_{i c t}
\end{aligned}
$$

offshore reflects the annual growth in offshoring across sector $i$ in country $c$ in time $t \cdot{ }^{14}$ Offshoring is defined as the share of imported intermediate goods and servicesexcluding energy intermediate inputs over the sum of intermediate goods and services-excluding energy intermediate inputs (Feenstra and Hanson 1996). Our variables of interest

\footnotetext{
${ }^{14}$ Growth is calculated as the $\log$ difference of the variable over the specified period.
} 
robot and robot $*$ labint capture the effects of the growth in robot stock and robots conditional on labour intensity on offshoring. We also include a number of control variables believed to be related to offshoring including growth in absorptive capacity (measured by patent stock) Absorb, and growth in Demand of the country and sector over time. Country*sector and year fixed effects are also included to control for economy industry as well as year variation over time.

\section{Robot Stock and Backshoring}

In Eq. (A.2) employment or fixed assets growth rate at home of company $i$ part of group $g$ in year $t$ is regressed over the aggregate growth rate of the same variable of affiliates abroad. The growth abroad variable abd is split in two variables $a b d \_p$ and $\_n$, depending on whether it takes a positive or negative value, respectively. Doing so allows the change in growth rate at home to be different in sign and magnitude depending on whether affiliates abroad are expanding or contracting, respectively.

If there is backshoring, the relationship is expected to be negative-i.e. an increase in employment or investment at home is associated with a decrease in employment or investments abroad. However, a negative association may actually be also a symptom of offshoring, i.e. a decrease in employment or investment at home is associated with an increase in employment or investments abroad. Therefore in this kind of analysis it is important to distinguish positive from negative changes in employment and fixed capital assets.

Interacting the growth abroad variables with relative robot stock of the group over the average affiliate $\left(a b d_{p} *\right.$ robot and $a b d_{n *}$ robot) allows us to assess the extent to which robots are contributing to the backshoring or resources within the MNE. If robotics contributes to backshoring one should expect to find a negative coefficient for the $a b d_{-} n_{g t} *$ robot variable. In order to examine whether robot use in the home country is related to backshoring here our robot measure represents the $\log$ different in robot stock of the country and sector of the headquarters over the average log difference of the robot stock for the sectors and countries of the affiliates abroad.

$$
\begin{array}{r}
\text { home }_{i g t}=a b d p_{i g t}+a b d n_{i g t}+a b d p_{i g t} * \text { robot } \\
+a b d n_{i g t} * \text { robot }+ \text { grpave } i g t+\delta_{i g t}+\varepsilon_{i t}
\end{array}
$$

\section{Robot Stock and Reallocation}

Equation (A.3) uses the same firm-level information on fixed capital and employment as in Eq. (A.2) for the dependent variable but now at the level of individual affiliates of MNEs signified by aff _ factor. This is regressed on robot stock of the affiliate country and sector. Control variables are also added, including growth in demand within the country $c$ sector $s$ and year $t$ of the affiliate, the average growth of the group (either employment or fixed assets) signified as factor and sector*year country*year fixed effects represented by $\vartheta$.

$$
\begin{aligned}
{\text { aff } \text { factor }_{\text {asct }}=\text { robot }_{c s t}+\text { demand }_{s c t}} & \text { factor }_{g s c t} \\
& +\vartheta_{t}+\varepsilon_{\text {asct }}
\end{aligned}
$$

\section{References}

Acemoglu, D., \& Restrepo, P. (2017). Robots and jobs: Evidence from US labor markets. NBER working paper 23285. doi: https://doi.org/ $10.3386 / \mathrm{w} 23285$

Baldwin, R. (2016). The great convergence: Information technology and the new globalization. Cambridge: Harvard University Press.

Brynjolfsson, B., \& McAfee, A. (2014). The second machine age: Work, progress and prosperity in a time of brilliant technologies. New York/London: W.W. Norton and Company.

Clifford, S. (2013). U.S. textile plants return, with floors largely empty of people. Available via The New York Times. Retrieved February 13, 2020, from https://www.nytimes.com/2013/09/20/business/ustextile-factories-return.html.

Dachs, B., \& Zanker, C. (2015). Backshoring of production activities in European manufacturing. MPRA paper 63868. Available via MPRA. Retrieved February 13, 2020, from https://mpra.ub.uni-muenchen.de/ 63868/1/MPRA_paper_63867.pdf.

De Backer, K., Desnoyers-James, I., Menon, C., \& Moussiegt, L. (2016). Reshoring: Myth or reality? OECD Science, Technology and Industry Policy Papers 27. doi: https://doi.org/10.1787/5jm56frbm38s-en.

De Backer, K., Destefano, T., Menon, T., \& Suhn, J. R. (2018) Industrial robotics and the global organisation of production. OECD Science, Technology and Industry Policy Papers 2018/03. doi: https://doi.org/ 10.1787/dd98ff58-en.

De Backer, K., \& Flaig, D. (2017) The future of global value chains: Business as usual or "a new normal"? OECD Science, Technology and Industry Policy Papers 41. doi: https://doi.org/10.1787/ d8da8760-en

Dedrick, J., Kraemer, K. L., \& Linden, G. (2010). Who profits from innovation in global value chains?: A study of the iPod and notebook PCs. Industrial and Corporate Change, 19(1), 81-116. https:// doi.org/10.1093/icc/dtp032.

Feenstra, R., \& Hanson, G. (1996). Globalization, outsourcing, and wage inequality. The American Economic Review, 86(2), 240-245. https://doi.org/10.3386/w5424.

Feenstra, R. C. (1998). Integration of trade and disintegration of production in the global economy. The Journal of Economic Perspectives, 12(4), 31-50. https://doi.org/10.1257/jep.12.4.31.

Finley, F., Bergbaum, A., Csicsila, A., Blaeser, J., Lim, L. H., Sun, Y., \& Bastin, Z. (2017). Homeward bound: Nearshoring continues, labour becomes a limiting factor, and automation takes root. Available via AlixPartners. Retrieved February 13, 2020, from https://emarketing.alixpartners.com/rs/emsimages/2017/pubs/EI/ AP_Strategic_Manufacturing_Sourcing_Homeward_Bound_Jan_ 2017.pdf.

Ford, M. (2009). The lights in the tunnel: Automation, accelerating technology and the economy of the future. United States: Acculant Publishing. 
Frey, C., \& Osborne, M. (2017). The future of employment: How susceptible are jobs to computerisation? Technological Forecasting and Social Change, 114(2017), 254-280. https://doi.org/10.1016/ j.techfore.2016.08.019.

Graetz, G., \& Michaels, G. (2015). Robots at work. CEP discussion paper 1335.

International Federation of Robotics (IFR). (2016a). Wold robotics report: Industrial robots. Frankfurt.

International Federation of Robotics (IFR). (2016b). World robotics report 2016: IFR press release. Frankfurt.

Lewis, C. (2014). Robots are starting to make offshoring less attractive. Available via Harvard Business Review. Retrieved February 13, 2020, from https://hbr.org/2014/05/robots-are-starting-to-makeoffshoring-less-attractive.

Linden, G., Kraemer, K. L., \& Dedrick, J. (2009). Who captures value in a global innovation network? The case of apple's iPod. Communications of the ACM, 52(3), 140-144. https://doi.org/10.1145/ 1467247.1467280.

Markoff, J. (2012). Skilled work, without the worker. Available via The New York Times. Retrieved February 13, 2020, from https:// www.nytimes.com/2012/08/19/business/new-wave-of-adept-robotsis-changing-global-industry.html.

OECD. (2013). Interconnected economies: Benefitting from global value chains. Paris: OECD Publishing. https://doi.org/10.1787/ 9789264189560-en.

OECD. (2016). The risk of automation for jobs in OECD countries: A comparative analysis. OECD Social, Employment and Migration Working Papers 189. doi: https://doi.org/10.1787/5jlz9h56dvq7-en.
OECD. (2017). Benefits and challenges of digitalising production. In: OECD (ed) The next production revolution: Implications for governments and business. OECD Publishing, Paris. doi: https://doi.org/ 10.1787/9789264271036-6-en.

Pricewaterhouse Coopers (PWC) (2014). The new hire: How a new generation of robots is transforming manufacturing. Available via PWC. Retrieved February 13, 2020, from https:// www.pwc.com/us/en/industrial-products/assets/industrial-robottrends-in-manufacturing-report.pdf.

Rodrik, D. (2015). Economics rules: Why economics works, when it fails, and how to tell the difference. Oxford: Oxford University Press.

Sirkin, H. L., Zinser, M., \& Rose, J. R. (2015). The robotics revolution: The next great leap in manufacturing. Available via CIRCABC. Retrieved February 13, 2020, from https:// circabc.europa.eu/sd/a/b3067f4e-ea5e-4864-9693-0645e5cbc053/ BCG_The_Robotics_Revolution_Sep_2015_tcm80-197133.pdf.

Tempest, R. (1996). Barbie and the world economy. Available via Los Angeles Times. Retrieved February 13, 2020, from https://www.latimes.com/archives/la-xpm-1996-09-22-mn-46610story.html.

The Economist. (2017). Adidas's high-tech factory brings production back to Germany. Available via The Economist. Retrieved February 13, 2020, from https://www.economist.com/business/2017/01/ 14/adidass-high-tech-factory-brings-production-back-to-germany.

UNCTAD. (2016). Robots and industrialization in developing countries. UNCTAD policy brief 50. Available via UNCTAD. Retrieved February 13, 2020, from https://unctad.org/en/PublicationsLibrary/ presspb2016d6_en.pdf.

WTO. (1998). Annual report. Geneva: WTO.

Open Access This chapter is licensed under the terms of the Creative Commons Attribution 4.0 International License (http://creativecommons. org/licenses/by/4.0/), which permits use, sharing, adaptation, distribution and reproduction in any medium or format, as long as you give appropriate credit to the original author(s) and the source, provide a link to the Creative Commons license and indicate if changes were made.

The images or other third party material in this chapter are included in the chapter's Creative Commons license, unless indicated otherwise in a credit line to the material. If material is not included in the chapter's Creative Commons license and your intended use is not permitted by statutory regulation or exceeds the permitted use, you will need to obtain permission directly from the copyright holder. 